\title{
Roberto Juarroz: la palabra enterrada
}

\author{
Alfredo SALDAÑA SAGREDO \\ Universidad de Zaragoza
}

\section{RESUMEN}

La escritura de Roberto Juarroz se sostiene sobre la simultaneidad y no sobre la alternancia, es palabra y silencio, materialización y promesa de diferentes realidades que el texto muestra u oculta entre sus líneas, sentidos satisfechos y posibilidad nunca saciada de sentido que remiten a una misma idea del texto poético como distancia jamás del todo recorrida. Y aunque esa escritura haya sido con frecuencia considerada como una poesía del pensamiento, filosófica, metafísica o cerebral, lo cierto es que esas etiquetas resultan finalmente demasiado rígidas y estrechas puesto que Juarroz apuesta por una poesía entendida como una "aventura a la intemperie" orientada hacia la búsqueda de los extremos que pueda alcanzar el ser humano, un lenguaje que insiste en su pretensión de explorar ese territorio, la profundidad, en donde la conciencia se disuelve, las palabras se adelgazan hasta casi desaparecer y cabe la posibilidad de no haber nada.

Palabras clave: poesía contemporánea, profundidad, indecibilidad, vacío.

\section{Roberto Juarroz: the buried word}

\begin{abstract}
Roberto Juarroz's writing is based on simultaneity rather than alternation, it is word and silence, materialization and promise of different realities that the text shows or conceals between its lines, satisfied senses and possibility of meaning never satisfied, which point to a notion of the poetic text as distance never completely covered. Although this writing has often been considered a poetry of thought, a philosophical, metaphysical or cerebral poetry, ultimately these labels prove to be too rigid and narrow because Juarroz chooses a poetry understood as "open-air adventure", oriented towards the search for the extremes that the human being can reach, a language that insists on its attempt to explore this territory, the depth, where conscience dissolves, words thin until they almost disappear, and there is the possibility that there might finally be nothing.
\end{abstract}

Key words: Contemporary poetry, Depth, Unspeakability, Void.

SUMARIO: 1.Sobre las conflictivas relaciones entre poesía y pensamiento. 2. La poesía como proyección de la otredad. 3. Juarroz et al. 4. En la verticalidad del abismo la nada florece. 5.Lenguaje poético y contrarrealidad. 


\section{Sobre las conflictivas relaciones entre poesía y pensamiento}

En el Tratado del Vacio Perfecto, de Lie Tse, puede leerse una sentencia que toma partido por la retirada, la inacción y la indiferencia y aconseja: "El mejor uso que se puede hacer de la palabra es callarse. La mejor acción es no actuar" (Lie Tse 49). A partir de esa premisa, qué nos queda sino reconocer y aceptar que la vida respira en el silencio y que en el lenguaje solo aflora su representación, apariencia y simulacro, un lenguaje que, en lugar de aportar sentidos, interviene restando potencialidades y funciona como una losa que estrangula con todo el peso de su tradición las posibilidades inéditas de la existencia. Sin embargo, en otras ocasiones las palabras se deshacen, optan por callarse y el silencio, al calor de la subversión, encuentra vías por las que poder ventilarse, no se pliega a las consignas de un sistema establecido, no acata ningún tipo de orden al manifestarse y, en su no decir, reclama por parte de quien lo escucha algún tipo de respuesta porque se presenta como un acto significativo de resistencia e insurrección.

Profesor de Bibliotecología y Documentación en la Facultad de Filosofía y letras de la Universidad de Buenos Aires durante una buena parte de su vida, ensayista, traductor, crítico literario y cinematográfico e impulsor de diversos proyectos editoriales y culturales, Roberto Juarroz (1925-1995) entendió siempre la palabra como una herramienta de generación de conflictos y de escenarios inéditos y llegó a ser ese poeta que - sin haber disfrutado nunca del favor de una recepción mayoritaria - desde muy pronto logró convocar la atención y el interés de un grupo más o menos reducido de lectores que encontró en su escritura un modelo de reflexión y compromiso permanentes con el lenguaje poético (entre ese enterado grupo de lectores incondicionales hallamos escritores como Vicente Aleixandre, Antonio Porchia, Julio Cortázar y Octavio Paz). Desde 1958, año en el que publica la Primera poesía vertical - y recordemos que ese, Poesía vertical, será el título que, acompañado del correspondiente ordinal, mantenga nuestro poeta a lo largo de toda su trayectoria hasta el décimo tercer y último volumen publicado en vida, aparecido en 1993 en edición bilingüe en Francia (en España, un año después)-, Roberto Juarroz no dejó de explorar en una poética fundada sobre un imposible, una especie de paradoja basada en la consigna: "el poema es presencia y ausencia a la vez" (Juarroz 2012: 317), una paradoja que convirtió en el centro de un pensamiento poético singular e insurgente y que funciona no tanto como un hábil juego lingüístico o un recurso retórico más sino como una puesta en cuestión de esas certezas que habitualmente nos rodean y que proporcionan aparentes dosis de seguridad (Peltzer 1996).

Es un hecho que, salvo muy meritorias excepciones, poesía y pensamiento han vivido en el contexto del español dándose la espalda con recíproca correspondencia. Quienes han dedicado algún tiempo a estudiar cuestiones relacionadas con la modernidad y la posmodernidad suelen coincidir en señalar que el ámbito hispánico -a una y otra orillas del Atlántico - se presenta como un desierto en cuanto al papel desempeñado por la cultura y el pensamiento en la construcción de ambas 
epistemes. Ese vivir al margen, cuando no en contra, de los grandes desafíos de la modernidad y la posmodernidad ha provocado en la cultura literaria española - $\mathrm{O}$ en español, pues ese lastre, repito, también se aprecia entre los escritores hispanoamericanos - una ausencia de reflexión y de pensamiento crítico y, si nos centramos en la poesía, se refleja en una carencia sobre la que siempre fue extremadamente consciente el propio Juarroz (1980: 39): "Extirpar el pensamiento de la creación poética la empobrece sin remedio" y, en otro lugar: "también el pensamiento cabe en la poesía" (Juarroz 2000: 23). Juarroz fue un escritor que desarrolló a menudo su trabajo poético en las inmediaciones de eso que él denominaba "mundo del pensar", hasta el punto de que su escritura, sin dejar de cantar y de contar, es decir, sin renunciar a la sonoridad y el ritmo del canto y a la linealidad y la discursividad de lo narrativo, se asienta fundamentalmente sobre ese tercer vértice que es el pensar, y ello con una coherencia radical, evitando la propaganda, el juego y el espectáculo, lo anecdótico e irrelevante de cualquier referencia personal, histórica, política, temporal o geográfica que pudiera restar a su escritura un ápice de densidad filosófica; de este modo, ese "despiadado proceso de revisión" al que, según Cerrato (ápud Juarroz 1996: 5), Juarroz sometía sus textos antes de publicarlos es una prueba más del compromiso y el elevado nivel de exigencia con el lenguaje que el argentino se demandaba a sí mismo.

En carta a W. S. Merwin, traductor de su obra al inglés, fechada el 26 de agosto de 1986, se refiere Juarroz a ese desapego hacia los elementos biográficos que pudieran desviar la atención de lo esencial de su poesía. Al mismo tiempo, encontró siempre en la soledad un venero para su escritura y esa actitud le llevó a considerarse siempre al margen de cualquier aventura colectiva: "no me siento vinculado o identificado con ninguna línea. [...] Y yo aspiro a la poesía verdadera, que será siempre soledad y encuentro en el misterio, pero no en las afiliaciones" (Juarroz 1980: 86). Al hilo de estas consideraciones, aunque en un plano más general, habría que recordar que Juarroz siempre tuvo en muy escasa consideración la actividad política, que entendió como el mayor adversario de la poesía, una práctica deshumanizadora orientada a vaciar al hombre de su singularidad para convertirlo en un muñeco, un miembro más de un rebaño (Juarroz 1975).

Así pues, nos encontramos, en el caso del poeta argentino, con una escritura dotada de una altísima densidad conceptual que demanda un lector liberado de prejuicios y estereotipos, dispuesto a romper con las más anquilosadas formas de concebir la lírica y a perderse entre los intersticios de un lenguaje atravesado de continuas paradojas, antítesis y contradicciones. Y aunque esa escritura haya sido con frecuencia considerada como una poesía del pensamiento, filosófica, metafisica o cerebral, lo cierto es que esas etiquetas resultan finalmente demasiado rígidas y estrechas puesto que Juarroz apuesta por una poesía entendida como un intento, una aproximación, una "aventura a la intemperie" orientada hacia la búsqueda de los extremos que pueda alcanzar el ser humano, un lenguaje que comienza a funcionar allí donde la lógica y la razón finalizan sus trabajos al encontrar sus límites, un 
lenguaje que, sin reblar, insiste y se arriesga en su pretensión de explorar ese territorio, la profundidad, en donde la conciencia se disuelve, las palabras se adelgazan hasta casi desaparecer y cabe la posibilidad, como avisara Antonio Porchia, de no haber nada. En estas circunstancias, Juarroz entendió su escritura como una obra en marcha, en construcción, y su poética, fundada sobre una cierta imposibilidad, no dejó de explorar en las conflictivas relaciones que se dan entre la palabra y el pensamiento, entre unas palabras que se muestran con frecuencia insuficientes o no alcanzan a dar testimonio de lo que sucede o resbalan y caen por su propio peso y un pensamiento entendido como una actividad que no se detiene.

\section{La poesía como proyección de la otredad}

En un mundo como el nuestro, en el que la teoría puede funcionar como una herramienta con la que cuestionar el orden natural de las cosas, un estado permanente de tensión y resistencia frente a cualquier forma de totalitarismo, es conveniente aceptar que la identidad cultural puede ser una categoría para el reconocimiento de las diferencias pero nunca una excusa para legitimar prácticas basadas en la desigualdad. Así, una vez abierta la grieta de la disparidad cultural, puede avanzarse hacia lo que se encuentra "más allá del simulacro" (Juarroz 2000: 24), hacia el reconocimiento de una metáfora comprehensiva de la otredad que revele tanto los efectos de la diferencia como las condiciones que pueden hacer posible el reconocimiento del otro y, finalmente, el entendimiento mutuo. Por ese itinerario han avanzado esos escritores que desde muy diferentes tradiciones culturales y al calor de diversas poéticas han desarrollado proyectos encaminados a situar al ser humano, como apuntaba Juarroz (1980: 25), "en su absoluto despojamiento", consistentes en la liberación de lastre identitario, convencidos de que ese lastre supone siempre una dificultad añadida en el intento de liberar el mundo de la losa de tópicos y prejuicios que lo mantiene estrangulado, pensándolo e imaginándolo de otra manera, proyectos que responderían a la afirmación: "La poesía es mi identidad" (Juarroz 1980: 82).

Juarroz avanzó por ese itinerario sin saber muy bien adónde le llevaría su escritura, quizás intuyendo que la profundidad implicaba una ruptura de los límites y que ese sin saber contenía ya un modo de sabiduría, convencido en todo caso de que la aventura pasaba necesariamente por una estrategia radical de vaciado: desactivar, deconstruir, desaprender, deshacer, desnombrar, desnudar, desandar, vaciar el mundo de las palabras que lo cubren y contemplarlo como si lo observáramos por primera vez, con una entremezclada sensación de inocencia, asombro y extrañeza, ingredientes de una poética que encontramos a menudo en Juarroz, como sucede en este poema del que copio ahora el comienzo y el final:

Desbautizar el mundo, sacrificar el nombre de las cosas para ganar su presencia. 
[...]

La palabra: ese cuerpo hacia todo.

La palabra: esos ojos abiertos. (Juarroz 2012: 189-190)

"desbautizar el mundo", acabar, como pedía el propio Juarroz, con el uso encallecido y en ocasiones encanallado de las palabras con la intención de recuperar la conexión íntima y perdida con la existencia. En este sentido, en el prólogo a la Tercera poesía vertical, Julio Cortázar (1965) pudo referirse a esa "sensación prodigiosa de extrañamiento" como una característica esencial de la escritura juarrociana (no es el momento ahora de recordar la importancia que a lo largo de la historia de las ideas literarias ha tenido siempre esa sensación, y no solo a partir de los trabajos de Shklovski). Juarroz no dejó de practicar ese sacrificio nominal de las cosas que derivase en una recuperación de su presencia, no cesó de forzar los límites del lenguaje con la intención de encontrar una nueva relación entre la palabra y lo que nombra que trajese consigo una refundación del mundo, el alcance verbal de una realidad inédita. El poema se cierra con un canto al destino potencialmente ilimitado de una palabra que se presenta como una mirada arrastrada por el asombro, cuyos ojos abiertos funcionan como la "principal ventana hacia el mundo, para recibirlo, incorporarlo a la compañía. Ojos abiertos, ojos receptivos" (Peltzer 1994: 57).

Ese viaje se materializa en ocasiones a través de la escritura poética, una actividad que, para Juarroz, es consecuencia de la intensidad y el amor a la vida, es capaz de acoger la última fe $\mathrm{y}$, frente a toda esperanza, la posibilidad de seguir esperando, una actividad que, al tensar los límites del hombre y del lenguaje, permite intuir que en la realidad hay acontecimientos que no encuentran representación en la pantalla de un ordenador, olvidados en el trastero de la historia, arrastrados incluso, como denunciara Juarroz (1980: 61), por "esa especie de discurso de la vida que distrae de la vida y aun llega a ocultarla", todo ello con la certeza de que "el revés es la zona/donde se encuentra todo lo perdido" (Juarroz 2012: 182); solo con acciones de este tipo se puede conseguir que la palabra se ponga en el lugar de aquello que no puede hablar, solo así se puede hacer de la poesía la manifestación de una cierta impersonalidad y no, como es habitual, el reflejo de una subjetividad centrada en el yo, dando de paso una mayor presencia a la otredad entendida como ese inmenso campo abonado de silencio que se encuentra al otro lado de nuestros límites y da cuenta de todas las carencias. En cierto modo, Juarroz intenta con su escritura desmontar el célebre aforismo de Ludwig Wittgenstein que puede leerse en el Tractatus (2002: 234): "Los límites de mi lenguaje significan los límites de mi mundo", y ese desmontaje precisamente puede llevarse a cabo tensando los límites del lenguaje hasta romperlos modificando así las fronteras del mundo, todo ello a partir de un pensamiento crítico, asistemático y roto, un pensamiento que encuentre la fortaleza en su fragilidad y elasticidad y que cuestione las estrategias retóricas, analíticas y 
conceptuales con que habitualmente interpretamos las cosas del mundo, una actividad que opere a partir de la premisa: "El pensar debe ser siempre otra cosa" (Juarroz 2012: 221). Ahí se encuentran el pensamiento y la otredad, y la poesía, en lo que tiene de exploración de la realidad desde los sótanos del lenguaje, puede desempeñar un papel decisivo. Ahí, en esa zona fronteriza, emergen los poemas de Juarroz no como unidades independientes sino como partes de un conjunto, fragmentos de una voz única e irrefrenable en el recorrido de su verticalidad ${ }^{1}$. De paso, finalmente habrá que reconocer que toda identidad incorpora la otredad y que cualquier conocimiento de uno mismo pasa por una labor de desanclaje y vaciado de tópicos, tal como nos muestra en uno de sus poemas R. Juarroz (1974: 51):

El otro que lleva mi nombre

ha comenzado a desconocerme.

Se despierta donde yo me duermo,

me duplica la persuasión de estar ausente,

ocupa mi lugar como si el otro fuera yo,

me copia en las vidrieras que no amo,

me agudiza las cuencas desistidas,

descoloca los signos que nos unen

y visita sin mí las otras versiones de la noche.

Imitando su ejemplo,

ahora empiezo yo a desconocerme.

Tal vez no exista otra manera

de comenzar a conocernos.

Este poema es una excepción en la escritura juarrociana puesto que el protagonista de la enunciación (y, en este caso, también del enunciado) es ese yo que aparece citado en el tercer verso; sin embargo, enseguida comprobamos que se trata de un sujeto en crisis cuya identidad no deja de tambalearse al someterse a un viaje de conocimiento que arranca a partir de una inicial acción de desconocimiento, de vaciado de la propia identidad, y ello en un escenario en el que la identidad es una categoría cultural en cuya configuración se entrelazan la mismidad y la otredad: desaprender para aprender, podría ser la fórmula que resumiera el sentido de ese viaje. Ahí emerge la palabra juarrociana como una oportunidad con la que desvelar aquello que permanece en el silencio y en el vacío y no tanto como un instrumento con el que representar el mundo: "Sacar la palabra

${ }^{1}$ En palabras de J. Rodríguez Padrón, estos poemas “generan un movimiento conjunto y definen con él los límites de un espacio cuyo ritmo interior viene determinado por la cohesión lograda entre esas unidades yuxtapuestas, declarando así la voluntad unitaria y progresiva que - aun en lo contradictorio - habita como fuerza matriz (y motriz) de esta poesía". 
del lugar de la palabra/y ponerla en el sitio de aquello que no habla" (Juarroz 2012: 285), donde la palabra "palabra" es sinécdoque de un lenguaje que, sin prejuicios, ha de deshacerse para reinventar de nuevo el mundo, un lenguaje que ha acabado convirtiéndose en uno de los ejes fundamentales sobre los que pivota esta escritura. Juarroz - que no se dejó nunca cegar por el deslumbramiento de florituras y fuegos de artificio, ajeno al vértigo de la forzada originalidad y contrario a la gratuita experimentación de novedosas e inconsistentes estrategias verbales - se encuentra entre esos autores que desafiaron con su poesía los límites del lenguaje y, al hacerlo, consiguió aproximarse a ese lugar en el que la palabra comienza a deshacerse y el silencio pugna por hacerse oír. Lo expresó el propio poeta con meridiana claridad, aunque esa claridad contuviera una forma de enigma y de secreto: "No se trata de hablar, no se trata de callar: se trata de abrir algo entre la palabra y el silencio" (Juarroz 1994).

\section{Juarroz et al.}

Podemos encontrar algunas similitudes entre Juarroz y Gaston Bachelard, sobre todo en lo concerniente a una idea de la poesía entendida como confluencia de imaginación e inteligencia, suma de emoción y reflexión ${ }^{2}$. Así, Juarroz pudo tomar de Bachelard la idea de la poesía entendida como una metafisica del instante y posteriormente, con una actitud que podría valorarse como una huella heredada del surrealismo histórico, se expresaría en términos parecidos al afirmar que la poesía es "la palabra en libertad y la palabra de la libertad" (Juarroz 2000: 49), la palabra, por añadidura, que vendría a suplir todas esas carencias que presentan las lenguas: "La poesía consiste, de alguna manera, en dar a todas las lenguas las palabras que les faltan" (Juarroz 1994). Esa red de vínculos e intereses comunes entre Juarroz y Bachelard podría muy bien ampliarse a María Zambrano y José Ángel Valente, de tal modo que en todos ellos encontramos elementos reveladores de un mismo imaginario poético. Valente, que comparte con Juarroz la búsqueda de esa nada esencial desde la que replantear la invención del mundo, mantiene con Zambrano una relación que se va a estrechar en la década de los setenta, cuando el poeta gallego ayude a la malagueña en la ordenación de Claros del bosque, libro de 1978 cuyo título - como es sabido- está tomado de la Lichtung heideggeriana y que remite a ese lugar abierto, como decía el pensador alemán, "libre para la presencia y

${ }^{2}$ El pensador francés (citado por el argentino en algunos de sus trabajos y con quien coincide en su concepción de la verticalidad del tiempo poético) afirma a menudo que el objetivo prioritario de la literatura consiste en renovar el lenguaje a través de la elaboración de nuevas imágenes: "Signifier autre chose et faire rêver autrement, telle est la double fonction de l'image littéraire" (Bachelard 1987: 283). De este modo, la poesía es, podríamos añadir con él frente a intolerantes y dogmáticos, un territorio adecuado donde ejercer la libertad: "la poesía contemporánea ha puesto la libertad en el cuerpo mismo del lenguaje. La poesía aparece entonces como un fenómeno de la libertad” (Bachelard 1994: 19). 
la ausencia", donde no siempre es posible entrar y donde, una vez dentro, acaso no se encuentre nada (como sucedía - lo he recordado más arriba - con esa profundidad evocada por A. Porchia en donde las palabras se adelgazan hasta casi desaparecer y cabe la posibilidad de no haber nada).

El Claro es el lugar de la escucha y no tanto el lugar de la visión, el lugar en donde la razón, exhausta, se desvanece de tanto y tanto trabajar por el bosque de la existencia (Maillard). Claro: lugar vacío, libre, donde es posible, no seguro, escuchar la palabra callada y encontrarse con la nada creadora, donde penetra quien ha logrado desidentificarse, vaciarse de cualquier tipo de identidad, liberarse de todos sus prejuicios en el "combate contra el orgullo o la necesidad de ser alguien" (Maillard 143), tan presentes en el imaginario occidental basado en la consigna "tanto tienes, tanto vales". Utilizo la expresión palabra callada no como un mero oxímoron sino en un sentido parecido al que encuentro en Juarroz cuando emplea el sintagma "escritura cegada"; en el fondo, se trataría de revelar la existencia de un lenguaje no por más soterrado menos real, un lenguaje que, lejos de someterse a una vida parásita, conserva todo su potencial indomable y creador:

La escritura cubre así otra escritura

y no deja de mirar hacia otro lado,

$[\ldots]$

Hay que cavar detrás de la escritura,

hasta encontrar la otra, la cegada. (Juarroz 2012: 230)

Palabras que pudieran servir también para calibrar la densidad de la escritura de Juarroz, un poeta que desarrolló desde el primer momento un proyecto de una coherencia aplastante basado en la cooperación de imágenes y conceptos y que se mostró siempre partidario de una poesía dispuesta en todo momento a abrirse y emplear una expresión insólita e inesperada, tocada de una cierta disponibilidad, entendida como "la apertura o entrega a cualquier cosa que pueda darse en la realidad" (Juarroz 2012: 21).

En un trabajo anterior (Saldaña) me he referido a cierta poesía como un viaje imaginario de regreso hacia la soledad y el silencio, esos lugares que, al tiempo que indican los puntos de donde habíamos partido, marcan también el destino de ese viaje. Soledad y silencio son dos puntales básicos en la escritura juarrociana: "No hay poesía sin silencio y sin soledad" (Juarroz 2000: 27), y en otro lugar: "Pensar es insistir/en una soledad sin retorno" (Juarroz 2012: 246); el silencio — junto a la nada, el abismo, la grieta, el salto y el límite - forma un entramado simbólico importante en una poesía como esta y remite a un espacio que puede cumplir diversas funciones: indicar el lugar del origen y la creación, señalar la incapacidad del lenguaje para nombrar el mundo, abrir el paso a la otredad, etc.; en cualquier caso, nos encontramos al final con una escritura que "abraza la posibilidad de reconquistar esa conjunción de palabra y silencio [...], e intenta la recuperación del 
silencio desde la poesía a partir de aquello que clama por ser una presencia, por manifestarse" (Sueiro). La soledad, por su parte, cultivada como un tesoro en los años de su primera juventud, acabará posteriormente imponiéndose como la columna vertebral de su escritura, lección que Juarroz pudo aprender del magisterio y el compañerismo cómplice de Antonio Porchia, cuya obra vino a confirmarle en la búsqueda de lo vertical, en la necesidad de escarbar hasta dar con esos estratos de la realidad que se encuentran más allá de lo aparente, una obra al hilo de la que Juarroz (1980: 167) declaró:

Llega un momento en que el lenguaje abandona su papel operativo e instrumental y pasa a ser prueba o caución de lo indecible. Y más todavía: pasa simplemente a ser. Es la culminación del lenguaje, que se convierte entonces en el hombre mismo y adquiere su mayor dimensión de realidad, exigencia y desnudez, terriblemente próximo al pensar y al silencio.

Con una coherencia y un rigor aplastantes, arropado por el silencio y acompañado de la soledad, Porchia escucha voces y con algunas de ellas se entrega a la construcción de una biografía en la que el lenguaje y el pensamiento caminan de la mano: "Mi libro Voces es casi una biografía. Que es casi de todos" (Porchia 182), declaración en la que el adverbio da paso a un escenario en donde la identidad del sujeto se disuelve en el palpitar colectivo. Por otra parte, ¿cuántas de esas voces no se quedarían por el camino, conservadas en la memoria de quienes pudieron escucharlas en la voz del propio Porchia, ajenas a la condena de la vida (im)presa?; al margen de cualquier concepción funcionarial o profesional de la escritura, Porchia utilizó siempre el lenguaje - yendo hacia él o dejando que fuera él quien se acercara - para expresar el asombro y el desconcierto ante el mundo, pivotó alrededor de sus Voces de una manera muy parecida a cómo Juarroz horadó en su Poesía vertical, ajenos ambos a todo tipo de consignas comerciales que, con la promesa de garantizar un puesto en el banquete del mercado literario, intentaran restar un ápice de crítica, libertad e imaginación a la palabra poética.

$\mathrm{Y}$ en esas circuntancias, la nada y el vacío son, más que metáforas, compañeros de un viaje que se emprende al hilo de una consigna orientada por la reducción. Habría que señalar en este sentido que Juarroz defendió siempre una escritura marcada por la renuncia, la desposesión y la pobreza, una poética orientada por la necesidad de romper el silencio únicamente cuando fuera inevitable: "solo hay que decir lo irreemplazable, lo que no se puede decir de otra manera" (ápud Ponzo); concibió así su escritura como una obra en construcción y se encontró siempre más próximo de una poética del fragmento en la que el balbuceo, la destrucción y la nada son elementos medulares, incluso germinadores, de su propia poesía que de una poética sistemática o de la totalidad, planteamientos que parece compartir, una vez más, con escritores como Celan, Jabès o Valente: 


\author{
Desgarrar el papel al escribir \\ para que desde el comienzo \\ asome por debajo el deterioro, \\ el desgaste, el hundimiento \\ al que se debe someter toda escritura. (Juarroz 2012: 218)
}

Así, se trataría de apostar por una poesía del desnombrar que emergiese como consecuencia del hundimiento, en un momento posterior a la caída, por debajo, una poesía que, consciente de la incertidumbre y el exilio que la acompañan, intuyese que más allá de los nombres que dan sentido a este mundo hay otro mundo que no se deja nombrar (Cerrato); se trataría de dinamitar las palabras que funcionan como un velo que impide el reconocimiento de esa otra realidad que permanece ahí, oculta, a la espera de ser desvelada a través de un lenguaje fundado sobre el desnombrar o el desbautizar; se trataría de comprometerse con la escritura hasta el punto no solo de dejarse la piel y las vísceras sino de disolverse en el papel, convirtiéndonos en materia textual, objeto del enunciado y consiguiendo así, como reclama Juarroz, que sea el texto quien nos lea y no al revés. En esas circunstancias, y al abrigo de la escritura de san Juan de la Cruz, la poesía sabe que la visión surge a partir de la suspensión de la mirada y que la palabra es protegida por el silencio. Juarroz, cuya escritura comparte algunos elementos con lo más telúrico, profano y laico de la mística (la exploración en el vacío existencial y su obsesión por nombrar lo innombrable), escribe: "Como una mano sin pareja se hundirá el pensamiento/y los ojos abiertos se usarán para no ver" (2012: 152), y en otro lugar: "No ver es solo otra visión" (2012: 300), detener las líneas de la representación, renunciar a fijar con la mirada los límites del mundo, hundirse en un pozo sin fondo. Se trataría de caminar exponiéndose al aire y a las inclemencias del camino, sin más, con la pretensión no de alcanzar ninguna meta sino de suspender la voluntad y lograr así ver tan solo lo que la luz de la oscuridad deje ver.

La poesía juarrociana se sostiene sobre la simultaneidad y no sobre la alternancia, es presencia y ausencia, palabra y silencio, materialización y promesa de diferentes realidades que el texto muestra u oculta entre sus líneas, sentidos satisfechos y posibilidad nunca saciada de sentido que remiten a una misma idea del texto poético como distancia jamás del todo recorrida. Así, al igual que ocurre con otros grandes escritores de nuestro tiempo (Maurice Blanchot, Paul Celan, Edmond Jabès, René Char, José Ángel Valente), Juarroz se sirve de algunos términos "imposibilidad", "indecibilidad", "exilio", "desierto", "blancura", "hueco", "nada", "sombra", "oscuridad", "agujero", "borradura", "abismo" y "silencio"- y con ellos elabora una poética articulada como un desafío del lenguaje a la posibilidad de su propia extinción, una poética con la que demanda la necesidad de "cultivar el vacío" (Juarroz 2012: 262) y que se presenta como "una visionaria y arriesgada tentativa de acceder a un espacio que ha desvelado y angustiado siempre al hombre: el espacio de lo imposible, que a veces parece también el espacio de lo indecible" 
(Juarroz 2000: 8), un lugar, en todo caso, muy cercano a la imaginación creadora que estudiara Gaston Bachelard y a ese espacio de lo sagrado que explorara María Zambrano; aproximarse siquiera a ese lugar exige tensar el pensamiento hasta el máximo posible pero sin que ello suponga desmantelar la razón para lograr mayores espacios de irracionalidad, pasa por hacer nuestra la paradoja de creer en la imposibilidad como revelación de la posibilidad, esto es, en palabras de Juarroz (1980: 98), se trataría de mantener "una especie de fe en la imposibilidad de hablar en profundidad de la poesía como revelación de la posibilidad de vivirla y crearla".

El poeta y ensayista argentino no eludió nunca ese compromiso consistente en la búsqueda de un lugar en el que vaciarse en un lenguaje llamado a desvelar la (in)consistencia de lo real; al margen de todo tipo de modas y consignas, Juarroz entendió la poesía no tanto como una actividad reglada sino como una oportunidad para adentrarse en un espacio vacío en el que plantear interrogantes de tipo metafísico y ontológico, donde, como señala Sánchez Aguilar (ápud Juarroz 2012: 79), "la nada se convierte en un símbolo que comparte ciertas características de lo divino: la nada original, la nada fundante, la ausencia previa a toda presencia", un espacio caracterizado por la apertura hacia lo simbólico e imaginario en el que el pensamiento se libera, sin adentrarse por ello en lo irracional, de la sistematicidad y la lógica de lo racional, en un proceso que culmina en un encuentro con la otredad en el que el yo deberá construirse a partir del vacío; y es precisamente en un texto perteneciente a una sección titulada "Poemas de otredad" donde encontramos uno de los numerosos ejemplos que hacen del interrogar, del cuestionar, una estrategia con la que, más que buscar respuestas, se persigue poner en tela de juicio la realidad, someterla a un estado de tensión permanente, vaciándola de paso de todo tipo de tópicos y prejuicios enquistados en el imaginario colectivo con el objetivo de crear un espacio vacío a partir del cual quizás sea posible reinventar la vida. Soltar lastre, vaciarse para permitir que de nuevo la vida entre en nosotros, convencidos de que el conocimiento requiere una labor previa de desaprendizaje, porque, como sugiere Porchia (92), "si no pudiera alejarme de mí, no podría acercarme a nadie, a nada. Ni a mí".

El vacío es lo que deja el tiempo tras haber arrastrado consigo el barro de la vida $\mathrm{y}$, en este caso, se trata del vacío dejado por la ausencia que habría de prolongar de un modo natural nuestra presencia. Por lo tanto habrá que afirmar — en contra de la opinión común - que quien calla no otorga sino dice, significa, contradicción tan solo aparente que han hecho suya algunos poetas centrales de nuestro tiempo al convertir el silencio en una poderosa herramienta de crítica y cuestionamiento, lección que hace suya Juarroz (2012: 317) cuando afirma: "Quien no sabe callar no sabe hablar. La poesía que no calla no puede decir nada". El silencio, que acoge a la nada, es entonces la materia interiorizada de la escritura, indica los límites de su extensión y abre el camino a una posibilidad que incorpora el riesgo de su propia imposibilidad; leemos en un poema de Juarroz (2012: 133): 
El centro es una ausencia, de punto, de infinito y aun de ausencia y solo se acierta con ausencia.

Emerge así una poética sustentada sobre la idea de que el centro carece de lugar, no tiene fijación ni posición en la que situarse y, por eso mismo, simboliza no tanto un punto de cierre o anclaje como el inicio de una apertura hacia lo que hay al otro lado, más allá.

\section{En la verticalidad del abismo la nada florece}

Esta idea abisal está presente, y de qué manera, en la poesía vertical de Juarroz, ya desde el propio sintagma que utilizó de manera reiterada en el título de sus entregas poéticas, en las que el abismo, en lo que tiene de espacio sin fondo, lugar sin cierre, denota tanto el intento de ir más allá de cualquier frontera como la verticalidad, la profundidad de un movimiento que habría de llevarle a descender a los intersticios del ser; la poesía se presenta así como una experiencia caracterizada por la profundidad con la que encaramos "los últimos límites de las últimas cosas: las tinieblas" (Juarroz 1980: 23), es el intento de expresar lo que de otro modo resulta imposible expresar; siendo lenguaje, la poesía supone asimismo un cierto contralenguaje o "la pretensión de ir con el lenguaje más allá del lenguaje" (Juarroz 1980: 103). Para Juarroz, la poesía de Porchia se presentó siempre como una extraordinaria oportunidad para reflexionar sobre la profundidad, "al borde de una obra que es la profundidad" (Juarroz 1975).

Ese título, Poesía vertical, refleja por otra parte muy a las claras la dirección de esta escritura, entendida, al margen de todo tipo de modas y tendencias, como una oportunidad radical para establecer un enfrentamiento sereno y riguroso con el lenguaje. Espacio sin fondo ese hacia el que nos arrastra esta poesía, que se presenta ya no tanto como el lenguaje llamado a revelar el enigma sino como el escenario en el que han de surgir nuevos y más profundos interrogantes y, en el caso de que lo tenga, se trata de un fondo que no cierra ni clausura nada sino que abre la herida de la posibilidad, indica la apertura de lo que no tiene nombre, de lo que es sin ser (todavía): "Sí, hay un fondo. Pero es el lugar donde empieza el otro lado" (Juarroz 2012: 127), un fondo que indica no un cierre sino el comienzo de un espacio todavía no hollado. A ese lugar nos arrastra esta poesía, un territorio que ha de premiar a quienes hasta allí lleguen no con la solución del enigma sino con la aparición de nuevos interrogantes. Jorge Rodríguez Padrón y Rafael Vargas, para quien la poesía juarrociana se presenta como "una proliferación de enigmas, una expansión del mundo hacia zonas verdaderamente insospechadas", entre otros, han visto en este rasgo una característica central de esta escritura.

Aunque se trata de un motivo recurrente en la historia de la poesía universal, ha sido sin embargo en la época contemporánea, a partir de algunos textos de Nietzsche y de Heidegger, cuando esa nada a la que más arriba me he referido ha 
adquirido una mayor relevancia hasta el punto de que algunos poetas relevantes de este tiempo la han convertido en el centro de su escritura, consolidándola como un motivo medular en la historia de la poesía y del pensamiento ${ }^{3}$. Juarroz (1996: 16) es uno de esos poetas y en un texto fechado en París el 22 de enero de 1993 podemos leer:

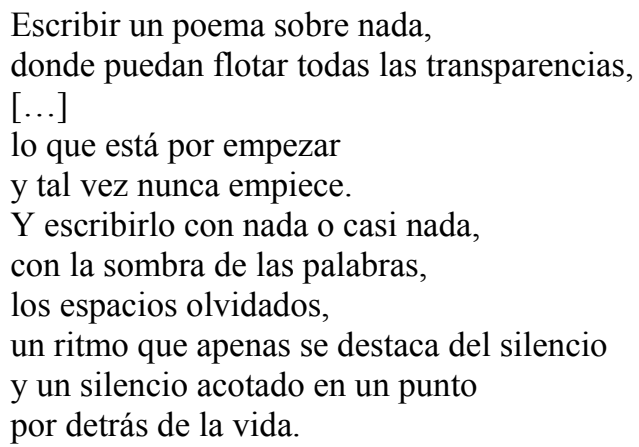

En todo caso, habría que señalar que dicho motivo no tiene por qué ser un síntoma de negatividad sino que ha de verse como el desarrollo de un proceso de desvalorización que se aprecia ya en Hölderlin, se intensifica en el "Igitur" mallarmeano y culmina en algunos programas estéticos de las vanguardias históricas como la representación simbólica de un lugar hueco a partir del cual es posible construir otras imágenes del mundo. Juarroz (2012: 207) escribe: "Hay que excavar la nada hasta borrarla,/[...]/Toda semilla será entonces un hueco", como si esa nada se encontrara enterrada en algún lugar bajo la superficie, al final de ese pozo sin fondo que lleva hacia el abismo, como si ese borrado fuese la previa condición que nos ha de permitir escribir otro mundo, con la certeza al final de que nuestra huella-escritura dará únicamente testimonio del vacío:

Todo pozo es una entrada al abismo.

No importa que tenga fondo

o aparente tenerlo:

un pozo es siempre la apertura a lo sin fondo. (Juarroz 2012: 277)

${ }^{3}$ La encontramos ya en ese moderno y memorable poema medieval de Guillermo de Aquitania (16 y 21) en el que tematiza la negación y la nada: "Farai un vers de dreit nien:/non er de mi ni d'autra gen,/non er d'amor ni de joven,/ni de ren au,/qu'enans fo trobatz en durmen/sus un chivau. [...] Fait ai lo vers, no sai de cui;/et trametrai lo a celui/que lo·m trametra per autrui/enves Peitau,/que·m tramezes del sieu estui/la contraclau", composición que versa sobre la "pura nada" (dreit nien), esto es, sobre algo que sin saber en qué consiste se entrega, se da como una clave para recibir a cambio un nuevo enigma, una contraclave. 
Sirviéndose de la paradoja, ese registro expresivo tan habitual en su escritura, Juarroz se refiere a esos espacios abisales y extremos en un poema que comienza y finaliza con los siguientes versos:

Hay una puerta abierta

y sin embargo hay que forzarla.

[...]

Hay que cerrar la única puerta

para poder tal vez entrar. (Juarroz 2012: 194-195)

Juarroz trabajó en todo momento por la construcción de un lenguaje poético desde el convencimiento de que solo desde la libertad se podían conquistar nuevos espacios de significación, un lenguaje que respondiera —en la medida de lo posible - al dictado de una imaginación no sometida y actuara sin tener en cuenta los sentidos, valores, prejuicios y condicionamientos previos que determinan habitualmente nuestro lenguaje corriente; en este sentido — diríamos hoy a partir de los trabajos de Derrida-, la poesía practica una cierta deconstrucción compartida con el habla de la locura pues ambas transgreden el orden sistemático de las convenciones y las significaciones sobre el que el discurso cristaliza y sitúan al lenguaje - $\mathrm{y}$ a quien lo usa - en su nivel superior de inocencia; se alcanza así un decir puro, sin condiciones al mismo tiempo que sin limitaciones, un decir liberado de cualquier tipo de intención y finalidad vinculadas a la comunicación. Juarroz también encuentra semejanzas entre la poesía, la mística y la locura:

¿Es la poesía un pretexto de la locura?

¿O es la locura un pretexto de la poesía?

$¿ \mathrm{O}$ las dos son un pretexto de otra cosa, de otra cosa excesivamente justa y que no puede hablar? (Juarroz 2000: 46)

Aunque en un sentido diferente, pues en este caso designa ese espacio indefinido que separa la vigilia del sueño, ese instante en el que la voluntad, las creencias y las certezas que acompañan a toda identidad quedan momentáneamente abolidas, también aquí la locura se imagina como un escenario vacío en el que ni siquiera el lenguaje tiene cabida:

La franja de locura

que despeña la vigilia en el sueño

es justamente eso:

la experiencia sin verbo

de una nada concreta. (Juarroz 2012: 252) 
Se habla aquí de establecer una poética radicalmente crítica y transformadora, entendida sobre la base de que el mundo será otro si son otros los usos y valores que se atribuyen a las palabras, una poética dispuesta a aproximarse a la raíz del sentido con el objetivo de remover hábitos, significados, conciencias. De nuevo Juarroz (2012: 276):
se trata de pensar de otro modo las cosas, palparlas de otro modo, abandonar las palabras que las usan y acudir a las palabras que las cantan, las palabras que las levantan en el viento como clavos ardiendo en el asombro.

En los Diálogos de Chuang Tse se advierte que el silencio se adueña del paisaje cuando el viento pierde fuerza y deja de agitar ramas, árboles, relieves y todo tipo de anfractuosidades del terreno; en realidad, allí se reconoce que el viento es silencioso y que el sonido no lo genera el propio viento sino que viene provocado por todos aquellos elementos que encuentra en su camino. Así pues, si el viento atravesara un espacio vacío, el silencio y no otra cosa sería lo que se oiría. Escritores como Jabès, Valente y Juarroz, que aprendieron muy pronto esta lección, comparten elementos imaginarios, simbólicos y filosóficos en lo que se refiere a sus concepciones de la poesía como una escritura articulada sobre un silencio que vela por lo desaparecido, es fuente incesante de posibilidades y, en el caso del argentino, se muestra capaz de devolvernos "el rostro desamparado que perdimos" (Juarroz 2012: 223). Como acertadamente viera Blanchot, en René Char y Paul Celan (dos poetas, sobre todo el primero, de quienes siempre se sintió muy próximo Juarroz) podemos encontrar un mismo gesto cuando se sirven de un lenguaje entrecortado y fragmentado, un lenguaje, como demanda Celan, hecho a veces de balbuceos e interrupciones y que con la imaginación y el deseo consigue dar forma a lo que Char (65) denomina "l'inextinguible réel incrée", una línea por la que con posterioridad han continuado explorando otros poetas, Juarroz entre ellos:

\footnotetext{
Romper también las palabras, $[\ldots]$

Y hablar entonces con fragmentos, hablar con pedazos de palabras, ya que de poco o nada ha servido hablar con las palabras enteras.
}

Reconquistar el olvidado balbuceo que hacía juego en el origen con las cosas y dejar que los pedazos se peguen después solos, como se sueldan los huesos y las ruinas. (Juarroz 2012: 261) 
Ruptura no solo sintáctica sino también léxica esta que aquí se propone y que culmina en una poética de la descomposición y el desmontaje que hace del fragmento su principal rasgo estilístico, una poética que, a la luz de maestros como Wallace Stevens o Antonio Porchia, intenta dar cuenta de esa otra realidad sustentada sobre la ruptura, la fugacidad, la intermitencia y la contradicción. Frente a un orden discursivo lineal y sistemático incapaz de dar cuenta de la historia o la verdad, la posibilidad de un escenario quebrado en el que los restos y residuos de las palabras recuperen todo su potencial dormido; en estas condiciones, de esta poesía podrá decirse no tanto que refleja un sistema como que expresa un pensamiento que, más allá de la lógica y la razón, debería entenderse como "una experiencia de global espiritualidad, suma de inteligencia y emoción, cruce de intuición relampagueante y paciencia especulativa" (Aguinaga).

\section{Lenguaje poético y contrarrealidad}

Un tema reiterado en la poesía contemporánea es ese que cuestiona la capacidad del lenguaje en su labor de fijación y control de la realidad, ese que designa la precariedad de todo saber fundado sobre la palabra. Juarroz - que fue siempre extremadamente riguroso en sus distinciones entre poesía y filosofía, poesía y mística e incluso poesía y literatura - es un buen exponente de esa escritura metapoética y dotada de una considerable densidad conceptual en el sentido de que en ella encontramos una permanente reflexión sobre el lenguaje y su disponibilidad para crear la realidad; metapoesía entendida no como una actividad solipsista, autorreferencial y ensimismada sino como un trabajo inagotable en el que el pensamiento no cesa de explorar el ser de la realidad, de tal modo que, como afirma D. Sánchez Aguilar (ápud Juarroz 2012: 27), "profundizar en lo metapoético significa para Juarroz profundizar en lo ontológico. Porque el espacio vacío que la imagen poética ha abierto en el espacio literario se convierte en espacio del ser". Se avanza así hacia una poesía en la que la palabra - desprovista de mundo, vaciada de apariencia de realidad - se presenta no tanto como un instrumento al servicio de la representación o la comunicación sino como una herramienta volcada hacia el desvelamiento de lo real, y en ese proceso, como defiende Juarroz, la poesía debe esforzarse en abrir la realidad quebrando la escala empequeñecida de lo real; es ese compromiso radical con la realidad el que le lleva a declarar: "la poesía es la máxima fidelidad a la realidad" (1980: 23) y, en otros lugares: "La poesía crea realidad, no ficción" (ápud González Dueñas y Toledo), "la poesía es el mayor realismo posible" (Juarroz 2000: 18), en la medida en que puede ir más allá de lo visible, que es solo una parte de lo real. En este sentido, es paradigmática, por lo radical, la actitud de Juarroz (1980), quien se mostró siempre bastante escéptico con respecto a esas lecturas e interpretaciones gregarias que, a la luz de todo tipo de modelos y reglas, pretenden encajonar a la poesía dentro de un determinado sistema; el escritor argentino, en la estela del Baudelaire que reivindicaba el punto de vista apasionado y subjetivo del crítico, apostó siempre por potenciar el 
componente creador de la crítica y, al calor precisamente de la idea de creación, distinguió entre lo que habitualmente denominamos literatura, una práctica discursiva sostenida sobre unos recursos y sometida a una retórica y unos preceptos determinados, y la poesía, esa "aventura de creación y conocimiento" (Juarroz 1980: 93) que explota al margen de cualquier sistema, que se da en los extremos, en los límites de la vida, que ofrece una idea de realidad más amplia que la que muestra el realismo en su acepción más magra, esa que habitualmente maneja una historiografia literaria que ha olvidado por el camino la presencia oculta y molesta de todos los desposeídos de la tierra; en palabras de Juarroz (2012: 316): "El realismo de la poesía, abierto al infinito, es lo opuesto al realismo estrecho e inevitablemente irreal que aparece en las historias de la literatura”. Una poesía, en suma, que abra las cosas, despojándolas de sus sentidos más trillados, exponiéndolas al desnudo, desprovistas de todas sus defensas, a la intemperie.

Pero toda regla tiene su excepción y ahí tenemos en este caso la idea de inefabilidad que alude a esa parte de la realidad que el lenguaje no puede expresar. Como es sabido, este conflicto entre la realidad y el lenguaje, entre las cosas y las palabras, ha sido una constante a lo largo de la historia del pensamiento (lo encontramos, por ejemplo, antes de que Horacio lo tratara en su Epístola a los Pisones y mucho antes de que Michel Foucault y otros pensadores contemporáneos se hicieran eco de él, en Chuang Tse, un filósofo y poeta chino del siglo IV antes de nuestra era - coetáneo pues de Platón—, discípulo de Lao Tse, el autor del Tao Te King), un dilema del que también se ha hecho eco Juarroz (2012: 255) en alguno de sus poemas:

Los nombres no designan a las cosas:

las envuelven, las sofocan.

Pero las cosas rompen

sus envolturas de palabras

y vuelven a estar ahí, desnudas,

esperando algo más que los nombres.

El sistema referencial se ha roto y palabras y cosas parecen habitar espacios asimétricos e incomunicables. En ese escenario, y frente a un lenguaje capaz solo de reprimir la vitalidad del mundo sin lograr desvelar su esencia, el mutismo parece una opción si no acertada al menos saludable. Creemos dominar el mundo delimitándolo con el envoltorio del lenguaje pero el mundo no se deja atrapar tan fácilmente. Somos lenguaje (palabra que nombramos, palabra que nos nombra), esto es, aire, viento con el que pretendemos sofocar la permanente ignición de un mundo que no deja de arder y de resurgir de sus propias cenizas; y mientras tanto hablamos, labramos la tierra con la palabra al tiempo que ignoramos que esa albura que es el silencio acabará imponiéndose sobre todas las palabras como la 
posibilidad que da paso al abismo y al vacío envolventes de la vida: "el silencio es también una pregunta" (Juarroz 2012: 314).

La escritura era para Jacques Derrida, y esta es una idea que fue en aumento hacia el final de su vida, una actividad crepuscular. En una de sus últimas intervenciones señaló: "Cada vez que dejo que algo parta, que tal huella salga de mí [...], vivo mi muerte en la escritura" (Derrida 30), y algo parecido apuntaba Juarroz (2000: 43), para quien "la poesía es una presencia ante la muerte". Escribir es entonces experimentar una imagen de la muerte, soltar un cierto lastre de vida, perder incluso la oportunidad de dictar otras palabras - , pero es una pérdida que conlleva una ganancia pues, en esto, no es más rico quien más atesora sino quien ha sabido crecer en la privación y la adversidad; escribir implica así una cierta labor de vaciado, desgaste y erosión: escribo, es decir, me borro, me pierdo, desaparezco tras mis palabras y les cedo a ellas todo el protagonismo porque sé que Lévinas tenía razón cuando afirmaba: "Toda obra es tanto más perfecta cuanto menos importa su autor" (Lévinas 35), una obra que en ocasiones se levanta sobre la retirada de la palabra. Al hilo de estas consideraciones, resulta oportuno recordar que Juarroz (1980) se sentía desconcertado cuando alguien le interrogaba sobre circunstancias concretas de su vida, su biografía, su historia personal, aspectos que consideraba irrelevantes para los demás: "Mucho más que las vinculaciones entre poesía y biografía interesa la relación entre la poesía y la vida interior" (Juarroz 1980: 55); la escritura poética no puede limitarse entonces a ser un reflejo de la biografía, la biología, la psicología y la historia de un determinado sujeto ${ }^{4}$. De este modo, cabría decir que la experiencia poética consiste en el desdoblamiento de una realidad inicial en una realidad imaginaria que no se deja atrapar, cuyo rostro desaparece al ser contemplado y cuya palabra es solo el anuncio de una voz futura, el aviso de una realidad que no se ha materializado aún. Avanzar por esa senda, como señala Juarroz (1980), solo es posible a partir del cumplimiento de ciertas condiciones: una idea de la poesía que implique una ruptura con la parte más aparente y visible de la realidad y desarrollada como una práctica indagatoria dirigida hacia ese hueco sin fondo de las cosas que denominamos vacio.

$\mathrm{Y}$ esa inquietante presencia del vacío — esa profundidad abisal que Juarroz bien pudo heredar de quien siempre consideró como uno de sus maestros, Antonio Porchia-, que algunos perciben como una falta, una carencia, la amenaza, en cualquier caso, de que algo ronda por ahí desafiando nuestros límites, y que otros interpretan como la antesala de una realidad distinta que hemos de colmar con inéditas imágenes, es un motivo recurrente en la poesía de R. Juarroz, donde el

${ }^{4}$ Como es sabido, esto es algo que, en el marco de la New Criticism, William K. Wimsatt denunció en su ensayo de 1946 The Intentional Fallacy y que desde entonces conocemos con la denominación de falacia biográfica. 
abismo da paso a un mundo que se presenta como un relato originado en la ausencia y sostenido sobre la nada:

El mundo es el segundo término

de una metáfora incompleta, una comparación

cuyo primer elemento se ha perdido.

¿Dónde está lo que era como el mundo?

¿Se fugó de la frase

o lo borramos?

¿O acaso la metáfora

estuvo siempre trunca? (Juarroz 2012: 166)

Ahí, en el horizonte sin fondo del vacío habita el sentido. Como quiera que hay poetas que son capaces de mirar y abismarse en ese vacío, las cosas que ven y reflejan en sus textos resultan en ocasiones extraordinarias, son los efectos de unas miradas creadoras que, como la que encontramos en este poema de Juarroz (2012: 135), no se limitan a representar la realidad que contemplan sino que contienen propuestas inéditas de mundos emergentes:

La nitidez secreta de las cosas

levanta un mundo nuevo en mi mirada, que también es secreta y lleva un mundo.

Palabra poética: creación de realidad. Se escribe, sí, a partir de una conmoción, una insatisfacción, a partir del deseo de superación de una determinada realidad o, en expresión de Juarroz (2000: 17-18), "la poesía crea más realidad, agrega realidad a la realidad, es realidad", sobredosis de realidad, contrarrealidad. Pero esa situación inicial debe vestirse (y todo vestido oculta algo) con palabras dado que eso - palabras y no otra cosa- es lo que leemos en los textos literarios; esto, sin embargo, no niega el hecho de que la poesía emerge allí donde el lenguaje se retira, da paso a la suspensión del habla y, con ella, a la posibilidad de la palabra. El lenguaje sería así la tapadera que oculta el silencio en el que emerge la poesía o, a la inversa, la poesía podría ser un contralenguaje —un antilenguaje, escribirá Juarroz- que late en el silencio que respira bajo las palabras. Como señala Luis Gruss (198-199), tocado por una cierta sensibilidad de raíz oriental: "La poesía es el lugar donde el silencio tiene espacio entre las palabras. [...] Escribir un poema es abrirse y es, también, vaciarse. Construir poesía es el arte de callar a tiempo". Vaciarse, entregarse sin condiciones al vacío, quizás con la vana esperanza de que allí, desposeídos de todo, pueda escucharse la última palabra poética: 


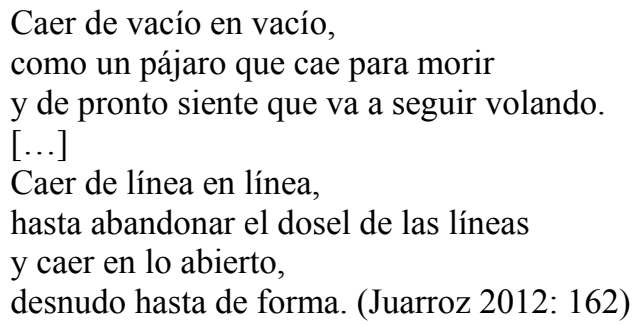

Como señalara Foucault en diversos lugares (Les mots et les choses, La pensée $d u$ dehors, L'ordre du discours), la literatura es un lenguaje que se niega a reconocerse en la imposición de unos rasgos identitarios particulares, un lenguaje que responde a un código que actúa como marco de referencia y al que permanentemente trata de vulnerar, un lenguaje, en palabras de Rancière (117), que "tiene como fundamento aquello que destruye su concepto, es decir, la literariedad", un lenguaje que guarda en su interior un virus letal que supone, si cabe hablar en estos términos, una amenaza permanente a su propia singularidad, incapaz por lo tanto de fijar unas fronteras seguras y estables y sometido a una constante labor crítica y erosiva. $\mathrm{Y}$ todos estos rasgos se aprecian con una intensidad considerable en algunas propuestas poéticas. Leemos en Juarroz (2012: 202):
Una palabra es todo el lenguaje, pero es también la fundación de todas las transgresiones del lenguaje, la base donde se afirma siempre un antilenguaje.

Somos así lo que ya hemos sido, lo que ya ha sido arrastrado por el torrente de la lengua hacia el océano del silencio; en ese sentido, el poeta responde a la fórmula menos es más y su trabajo consiste en una técnica de adelgazamiento según la cual las palabras que nos ofrece son imágenes de la vida que va perdiendo por el camino, una pérdida que, sin embargo, conlleva una ganancia puesto que, como respondiera Juarroz en 1985 a una encuesta del diario parisino Libération: "Yo escribo simplemente porque amo la vida", declaración que puede glosarse comentando que, para amantes de ese tipo, la escritura representa siempre una sobredosis, un exceso de vida y que encuentra un buen complemento en este aviso a navegantes: "No se escribe para publicar sino para vivir" (Juarroz 1980: 80), aunque a algunos les vaya la vida en ello. En expresión de M. Zambrano (46): "El poeta no pide, sino que entrega; el poeta es todo concesión", actitud que asimismo encontramos en Juarroz, quien a lo largo de toda su trayectoria - en su poesía, en sus ensayos, en las entrevistas que concedió, etc.- demostró siempre una acusada conciencia lingüística, un compromiso radical con la vitalidad de las palabras: 
Cuando uno ha ido aprendiendo ese humilde, ese tremendo oficio de ir amando las palabras, de no conformarse con el valor de mercado de las palabras, de no resignarse a las palabras como instrumentos desgastados, ni siquiera como instrumentos, sino también sentirlas como seres vivos, reconocerlas como pequeños animales que tenemos en las manos o en la boca o en el alma, entonces el manejo o la entrega a todo eso es algo muy decisivo, muy grave, porque no admite la superficialidad, el apuro. (Juarroz 1980: 80-81)

A partir de estas ideas, eso que comúnmente se entiende por "ser poeta" podría equipararse con vivir una especie de condena, experimentar un tipo de maldición que implique mantener una relación incondicional, permanente y rigurosa con el lenguaje, una relación que han resistido muy pocos y en la que algunos se han dejado eso que, precisamente, demanda la poesía: la vida; en palabras de Juarroz (1980: 59): "el lenguaje es una exigencia, una exigencia sin límites". En otro lugar, el poeta argentino lo expresó sirviéndose de la imagen de un viaje que —una vez traspasado cierto punto - no admite la posibilidad de la vuelta atrás:

Ir hasta el extremo es quedarse sin lugar,

porque el extremo no es un lugar,

más allá no hay espacio

y quien fue hasta el extremo

no puede ya retroceder.

Ir hasta el extremo consiste precisamente

en hallar la imposibilidad del regreso.

O quizá tan sólo

la imposibilidad.

Y lo imposible no necesita lugar. (Juarroz 1974: 57)

La poética juarrociana pudiera muy bien condensarse en uno de sus versos: "romper el límite" (Juarroz 1996: 17), una actividad que implica un esfuerzo por ampliar el espacio hasta el punto de afrontar el desafío de "quedarse sin lugar", desubicado, ir hasta ese lugar-sin lugar donde el silencio da testimonio de lo que falta, de lo que hay más allá, de lo que vive amenazado por la navaja que corta y amputa y sirve solo al sentido común, de lo (im)posible, de lo que respira con dificultad bajo las piedras y de lo que se alimenta con la materia que da forma al deseo. Habitar ese lugar marcado por la imposibilidad es asumir el riesgo de la desaparición.

Al tratarse de una escritura que "procede por inversión de signos" (Cortázar), la poesía juarrociana es una permanente puesta en tela de juicio de la trivial y limitada acepción de un realismo garante de un orden social y económico al servicio del poder establecido al tiempo que vinculado casi siempre a lo experimental, figurativo y sentimental de la realidad; al mismo tiempo, representa un aviso a navegantes sobre la necesidad de encontrar fórmulas alternativas que nos permitan 
construir una nueva relación con la realidad que sea capaz de detectar esas zonas no por oscuras e invisibles a simple vista menos reales, con la certeza, como defiende el poeta argentino, de que "lo invisible no es la negación de lo visible,/sino tan solo su inversión y su meta" (Juarroz 2012: 186). Se trataría, pues, de reivindicar un trato con la realidad más amplio que el que ofrece el realismo en su sentido más estrecho y alicorto, ese que funciona como una especie de reflejo prescriptivo, fiel, exacto, normativo y naturalista de una realidad que existe con anterioridad a nuestra intervención y emerge únicamente para ser imitada. Brota así, como quería Juarroz (2000: 25), la poesía entendida como "la vida no fosilizada o desfosilizada del lenguaje", una poesía, al calor de la resistencia pasiva postulada por Gandhi, concebida como "una interminable forma de no entregarse, de no aceptar" (Juarroz 1994). Poner en crisis al sujeto, enfrentándolo a todas esas pertenencias y adquisiciones que ha ido atesorando a lo largo del tiempo y con las que ha ido tejiendo su particular identidad, entrar en contradicción con la propia seguridad, cuestionar ese mecanismo que nos singulariza como entidades compactas, fuertes y homogéneas, tales pudieran ser algunos objetivos de una poesía edificada sobre la inestabilidad, dispuesta a cruzar fronteras y a escuchar los latidos de la incertidumbre, situándose así en otra dimensión, en "un más allá del yo", como demandara Juarroz (2012: 317).

Propuestas de escritura como esta suponen un auténtico desafío para una crítica y una historiografía literarias excesivamente acostumbradas a trabajar con patrones demasiado rígidos $\mathrm{y}$, en este sentido, el propio Juarroz apostó por cambiar el curso de la historia literaria al proponer que las historias de la literatura al uso se sustituyeran por el estudio de los autores más singulares, dotados de un componente creador capaz de romper todos los moldes, desafiar todas las estrategias analíticas. Las palabras del poeta argentino, publicadas por primera vez en 1960, podrían muy bien referirse a la crítica poética que se ejerce hoy, y me temo que no solo en Argentina:

La crítica actual de la poesía en nuestro país peca, en primer término, por una absurda y pretenciosa desconfianza hacia los fundamentos. El resultado es una enorme superficialidad en una enorme verborragia. Lo insubstancial, lo rutinario, lo partidista, lo pedante, lo demagógico y algunas veces lo erudito llenan los cangilones de una noria que sigue girando con provincial chirrido. [...] Eso hace que se plantee lo literario en otras instancias (lo sociológico, lo político, lo filosófico, lo ético, lo histórico, lo religioso, etc.), trasladando así abusivamente el plano de su criterio de validez y sus coordenadas básicas de referencia. En el fondo, se trata de otra crisis de los fundamentos y de un significativo complejo de inseguridad. Por eso, la mayor parte de la crítica de la poesía nos habla de cualquier cosa, pero no de poesía. (Juarroz 1980: 157 y 159)

En sus planteamientos críticos, cercanos en ocasiones a algunos defendidos por el más reciente comparatismo literario, Juarroz apostó siempre por la singularidad y 
por la abolición de todo tipo de fronteras y divisiones más o menos convencionales o artificiales; así, su mirada fue siempre más allá de esa otra interpretación nacionalista, excluyente y segregacionista, de corto vuelo y horizonte estrecho que todavía hoy se extiende como una propuesta mayoritaria y dominante:

Hablar de una literatura argentina, como podríamos hablar de una literatura española, es una separación superficial. En todo arte, lo que importa es la visión global de lo que ocurre en el mundo del hombre, una visión transnacional. Lo digo con una palabra muy al uso: una visión "comparativa". En lo literario hay, sí, calidades, pero no nacionalidades, ni femenino o masculino. (ápud Vargas)

Juarroz apuesta por desmantelar una crítica que parece haber renunciado a explorar la profundidad del abismo que plantea cierta poesía y recuperar así una crítica liberada de toda jerga de escuela y no sometida a las imposiciones de ningún ámbito extraliterario. Bajo la aparente calma y uniformidad de la voz más sobredimensionada se escuchan otras voces que descubren las grietas y la polifonía - las diferencias y, en el fondo, las desigualdades - de toda sociedad y son esas grietas, como decía Juarroz (2012: 272), las que debe cultivar el poeta como espacios vacíos donde "juntar lo que no existe".

Habitar ese territorio en el que las palabras son insuficientes o no dan testimonio de lo que pasa o resbalan y caen por su propio peso, ese lugar en el que el pensar no se detiene y el hablar se hace más y más dificultoso, ese es el desafío que algunos escritores han asumido en su trabajo. Juarroz es uno de ellos, un escritor que no deja de merodear en los límites de la palabra, junto a ese inquietante campo abonado por el silencio, y al hacer eso mantiene vínculos con ciertas tradiciones culturales alejadas entre sí en el tiempo y en el espacio pero unidas por una misma sabiduría que ha renunciado a saber y que encontramos en algunos capítulos del Tao, el budismo Zen y determinadas corrientes más o menos heterodoxas de la mística cristiana, judía y musulmana. $\mathrm{Y}$ en ese escenario nos situamos cuando leemos ciertos textos literarios que hacen de la imposibilidad, la indecibilidad y la contradicción sus bases más sólidas. En esos casos, la literatura "desemboca en lo impensable" (Lévinas 39), invoca, como propusiera Blanchot, el signo de la piedra, el desierto y el silencio o, dicho con otras palabras, solo puede ser medida a partir de un pensamiento poético no sometido llamado a liberar la historia del peso de $s u$ historia, orientado a impulsar la posibilidad de un mundo inédito, y para llevar a cabo ese proceso es preciso desprenderse de todo lastre, desterrar del mundo todas las palabras que a lo largo de la historia lo han cercado, "retroceder de todos los lenguajes" (Juarroz 2012: 302) con la intención de iniciar un camino inédito.

Abría estas páginas con unas palabras del Tratado del Vacio Perfecto, ahora las cierro con otras tomadas del Tao Te King, donde se lee: "Hablar poco es lo natural" (Lao Tse 35). Entonces, si lo natural es hablar con mesura, ¿por qué empeñarnos en borrar el mundo con el manto al mismo tiempo verborrágico y huero del lenguaje?, 
¿por qué insistir en quebrar el orden original del silencio con el ruido inane de las palabras? Propuestas poéticas como la que Juarroz llevó a cabo con intensidad y rigor considerables son un buen ejemplo de lo que debería ser una relación radical con la palabra, una relación en la que la acción y el acontecimiento consistan en escribir solo y sólo cuando sea inevitable, cuando estemos atrapados y no quepa otra salida entre el silencio y la desesperación, aun con la certeza de que el conocimiento del mundo - como pensaba Celan- es deudor del conocimiento de las palabras, aún con la trémula esperanza de que al final — después de todo, tras la puerta que da paso al tiempo de las pérdidas y las reconciliaciones - haya alguien ahí, en ese lugar ocupado ahora por el poema y del que el poeta, sólo un hombre solo, ya ha sido desplazado. Escribir así, juntando unas palabras con otras después de haberlas desmembrado, sin la servidumbre que impone la constitución del sentido, con la sensación de estar dando forma e imagen al mundo por vez primera, atravesando una distancia en la que el final solo marca el regreso permanente a la palabra originaria.

\section{BIBLIOGRAFÍA}

Aguinaga, Luis Vicente.

s. f. "Cercanía de Roberto Juarroz"

[http://www.robertojuarroz.com/ensayos6.htm].

AQUitania, Guillermo de.

1983 Poesía completa, ed. de L. A. de Cuenca. Madrid: Siruela.

BACHELARD, Gaston.

1987 L'air et les songes. Essai sur l'imagination du mouvement. París: José Corti.

1994 La poética del espacio. trad. de E. de Champourcin. Madrid: FCE. BLANCHOT, Maurice.

1999 La bestia de Lascaux. El último en hablar. trad. de A. Ruiz de Samaniego, nota de presentación de J. Jiménez. Madrid: Tecnos.

Cerrato, Laura.

1985 Ensayos sobre poesía comparada. Buenos Aires: Botella al Mar.

CHAR, René.

1980 Fureur et mystère. Pref. de Y. Berger. París,:Gallimard. CORTÁZAR, Julio.

1965 "Carta-prólogo", en R. Juarroz, Tercera poesía vertical. Buenos Aires: Equis [http://www.robertojuarroz.com/ensayos1.htm].

DERRIDA, Jacques.

2006 Aprender por fin a vivir. Trad. de N. Bersihand. Buenos Aires: Amorrortu. 
GONZÁLEZ DUEÑAS, Daniel, y Alejandro TOLEDO.

1987 "El horizonte vertical. Una conversación con Roberto Juarroz" [http://www.robertojuarroz.com/conferencia2.htm].

GRUSS, Luis.

2010 El silencio. Lo invisible en la vida y el arte. Buenos Aires: Capital Intelectual.

JUARROZ, Roberto.

1974 Poesía vertical. Barcelona: Barral Editores.

1975 "Antonio Porchia o la profundidad recuperada"

[http://www.robertojuarroz.com/ensayos11.htm].

1980 Poesía y creación. Diálogos con Guillermo Boido. Buenos Aires: Carlos Lohlé.

1994 "Aproximaciones a la poesía moderna" [http://www.robertojuarroz.com/conferencial.htm].

1996 Decimocuarta poesía vertical. Quince poemas. Pról. de L. Cerrato. Sevilla: Ayuntamiento de Carmona.

2000 Poesia y Realidad. Valencia: Pre-Textos.

2012 Poesía vertical. Ed. de D. Sánchez Aguilar. Madrid: Cátedra.

LAO TSE.

1979 Tao Te King. Madrid: Editorial Ricardo Aguilera/Luis Cárcamo, Editor.

LÉVINAS, Emmanuel.

2000 Sobre Maurice Blanchot Ed. de J. M. Cuesta Abad. Madrid: Trotta. LIE TSE.

2006 Tratado del Vacio Perfecto. Trad. de L. Wieger, versión de E. Serra. Palma de Mallorca: José J. de Olañeta, Editor.

MAILlARD, Chantal.

1992 La creación por la metáfora. Introducción a la razón poética. Barcelona: Anthropos.

PELTZER, Federico.

1994 Poesía sobre la poesía (en la literatura argentina contemporánea). Buenos Aires: Botella al Mar.

1996 "Desbautizar el mundo: una introducción a la poética de Roberto Juarroz" [http://www.robertojuarroz.com/ensayos8.htm].

PONZO, Alberto Luis.

1984 "La poesía es el mayor realismo posible" (entrevista a Roberto Juarroz realizada el 16 de noviembre de 1984)

[http://www.robertojuarroz.com/conferencia9.htm].

PORCHIA, Antonio.

2006 Voces reunidas. Ed., pról., tabla de variantes, anexo y epíl. de D. González Dueñas y A. Toledo con la colaboración de Á. Ros. Valencia: Pre-Textos. 
RANCIÈRE, Jacques.

2009 La palabra muda. Ensayo sobre las contradicciones de la literatura. Trad. de C. González. Buenos Aires: Eterna Cadencia Editora.

RODRÍGUEZ PADRÓN, Jorge.

s. f. "La aventura poética de Roberto Juarroz" [http://www.robertojuarroz.com/ensayos2.htm].

SAÑDAÑA, Alfredo.

2008 Hay alguien ahí. Zaragoza: Olifante/Papeles de Trasmoz. SUEIRO, Noelia.

s. f. "Los extremos de la palabra"

[http://www.robertojuarroz.com/ensayos10.htm].

VARGAS, Martha.

s. f. "Palabra y silencio intermediarios de lo absoluto. Conversación con Roberto Juarroz"

[http://www.robertojuarroz.com/conferencia8.htm].

VARGAS, Rafael.

1987 "Novena poesía vertical"

[http://www.robertojuarroz.com/ensayos5.htm].

WITTGENSTEIN, Ludwig.

2002 Tractatus logico-philosophicus. Trad., intr. y notas de L. M. Valdés Villanueva. Madrid: Tecnos.

ZAMBRANO, María.

1996 Filosofía y poesía. México: FCE. 